\title{
The effects of controllability on extinction
}

\author{
RICHARD S. CALEF, DONALD W. MURRAY, PRESTON D. MODLIN, \\ and BYARR W. MEEKINS \\ West Virginia Wesleyan College, Buckhannon, West Virginia 26201 \\ and \\ E. SCOTT GELLER \\ Virginia Polytechnic Institute and State University, Blacksburg, Virginia 24061
}

\begin{abstract}
During Phase 1, 30 rats were given CRF training in a straight runway. During Phase 2, subjects received contingent reinforcement (food), noncontingent reinforcement, or no treatment in an operant chamber. The results, which supported a "learned helplessness" interpretation, showed the noncontingent group to be the most resistant to extinction in the alley during Phase 3.
\end{abstract}

Dogs exposed to inescapable (uncontrollable) shock in a Pavlovian hammock showed interference with later escape learning in the shuttlebox, compared with subjects receiving an equivalent amount of prior escapable (controllable) shock or no shock. This phenomenon has been called the "learned helplessness" effect (Overmier \& Seligman, 1967; Seligman \& Maier, 1967). Recently, learned helplessness has been applied to an appetitive situation in which deficits in instrumental responding for food were also observed in rats who were given prior exposure to noncontingent- food (Seligman, 1975; Wheatley, Walker, \& Miles, 1977).

The main interest of the present study was to investigate whether the learned helplessness model could be extended to predicting performance during the extinction of a food-rewarded response. For example, if nonresponding is a voluntary instrumental response, then animals presented with noncontrollability (i.e., noncontingent food or inescapable shock) should be more resistant to extinction (interference with nonresponding) than animals given controllability or no treatment. However, Rosellini and Seligman (1975) found no effects of controllability of shock on food-reward extinction. Rosellini and Seligman contended that simple exposure to aversive stimulation, whether controllable or uncontrollable, may have resulted in some habituation to the aversive stimulus. This habituation possibly generalized to other aversive stimuli (extinction or frustration) and produced equal amounts of resistance to extinction for rats who were given inescapable shock and those who were given escapable shock.

The purpose of the present study was to ascertain whether uncontrollability produced through noncontingent reinforcement would show the most resistance to food-rewarded extinction when habituation to a previously aversive stimulus would not occur.

Reprint requests should be sent to Richard S. Calef, West Virginia Wesleyan College, Buckhannon, West Virginia 26201.

\section{METHOD}

\section{Subjects}

The subjects were 30 experimentally naive male albino rats of the Sprague-Dawley strain, approximately 90 days old at the beginning of the experiment. The animals were acquired from Flow Laboratories, Dublin, Virginia, at which they had been bred and reared.

\section{Apparatus}

The runway apparatus was essentially the same as that used by Ludvigson and Gay (1966), except that only one of the multiple parallel alleys was used. The alley was composed of a $33.02-\mathrm{cm}$ gray startbox, a $66.04-\mathrm{cm}$ gray runway section, and a $33.48-\mathrm{cm}$ gray goalbox. The inner width and height of each section of the runway were $7.62 \mathrm{~cm}$. Photocell and clock circuitry provided an independent measure of traversal time over the last $45.72-\mathrm{cm}$ segment of the run section. The apparatus contained a gray retrace door, separating the goal from the alley section, and an opaque Plexiglas ceiling.

The three operant chambers used were $19.6 \mathrm{~cm}$ wide, $18 \mathrm{~cm}$ high, and $29 \mathrm{~cm}$ long. The sides of the chambers and the ceilings were constructed of clear Plexiglas. Centered on the right-hand panel was a lever $(5 \mathrm{~cm})$ that was $5.5 \mathrm{~cm}$ above the floor. To the right of the lever was a square metal goal cup that extended to the outside of the chamber so that the experimenter could manually place pellets in it. The goal cup was approximately $5 \mathrm{~cm}$ above the floor.

\section{Procedure}

Fourteen days prior to the 1st day of training (Day 15), all rats were placed on a 23-h food-deprivation schedule, which was maintained throughout the study. On Days 7-14, the rats were taken from their individual home cages and handled for about 2 min each. On Days 13 and 14, the rats were taken to the experimental laboratory, where they were allowed to explore start and run sections of the apparatus while the clocks, photocells, and doors were operated. On those days, approximately $1 \mathrm{~g}$ of $45-\mathrm{mg}$ Noyes pellets, identical to the subsequent reinforcement pellets, was incorporated into the rats' daily food ration.

During Phase 1, all animals were given 60 trials ( 5 trials/day) of continuous reinforcement (CRF) training (4 pellets) in the straight runway. Following Phase 1 , the subjects were matched in triads according to the runway speed and then randomly assigned to one of three groups (10 rats/group).

During Phase 2, a yoked-control design was employed (.5 h/day for 3 days) in which Group C (contingent, or controllable, condition) was shaped to barpress (the response lever 
was baited with a single pellet for 10 trials) for one pellet per response in an operant chamber, and Group NC (noncontingent, or noncontrollable, condition) received noncontingent reward in another operant chamber at the same time Group $C$ earned its food. In other words, amount of food was yoked. When a subject from Group C barpressed, both that subject and its "partner" from Group NC received a pellet in the goal cup. Group NT (no treatment) received no food but occupied an operant chamber (which also contained a lever and a goal cup similar to that of the other chambers) during the same time of day (.5 h/day for 3 days) when Groups $\mathrm{C}$ and NC were treated.

In Phase 3, all the subjects were given extinction (no-reward) training in the straight runway. At this time, all animals were detained in the goalbox for a 20 -sec period before being returned to their home cages.

During Phases 1 and 3, trials were administered to five squads of six rats from each group. The running order of subjects within a squad was randomized from day to day. The intertrial interval was approximately $10 \mathrm{~min}$ during Phase 1 and $20 \mathrm{~min}$ during Phase 3 , since a subject did not receive its second daily trial until all subjects in the squad had completed the first trial. The running trials during Phases 1 and 3 were initiated by placing the rat in the startbox. After a 3 -sec orientation period, the start door was opened and the rat was allowed to traverse the runway. Following the rat's entry into the goalbox, the retrace door was dropped. Following consumption of the pellet or confinement for $20 \mathrm{sec}$ (Phases 1 and 3, respectively), the rat was removed from the apparatus to a nearby wire-mesh cage to await the next trial.

\section{RESULTS}

\section{Phase 1: Runway Training}

Run times were converted to reciprocals, yielding run speeds. Figure 1 illustrates group mean speeds as a function of five-trial blocks.

As can be seen in Figure 1, all three groups of rats were running at approximately the same speed during the last three blocks of Phase 1. A simple analysis of variance was performed across the data from Blocks 10 , 11 , and 12. The analysis showed no reliable effects $(\mathrm{p}>.10)$.

\section{Phase 2: Operant Training}

All the subjects in Group C learned to barpress. On Days 1,2 , and 3 , Group $C$ barpressed at average rates of 5,7 , and 8 presses $/ \mathrm{min}$, respectively.

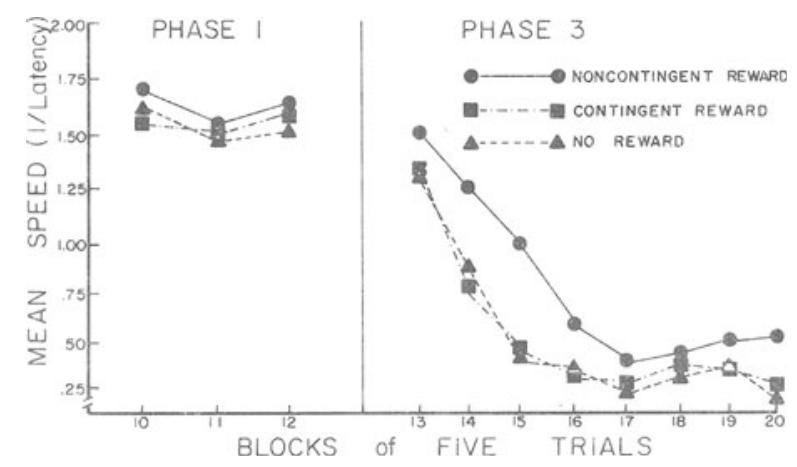

Figure 1. Group mean alley speeds as a function of blocks of five trials for subjects receiving noncontingent (Group NC) and contingent (Group $C$ ) reinforcement and no treatment (Group NT) in an operant chamber.

\section{Phase 3: Extinction}

As can be seen in Figure 1, Group NC showed faster speeds than Groups $\mathrm{C}$ and NT throughout extinction. A 3 (groups) by 3 (blocks) factorial analysis was performed on the data from Blocks 14, 15, and 20. The analysis yielded a significant groups effect $[F(2,27)=$ $4.23, \mathrm{p}<.05]$, a significant effect of blocks $[\mathrm{F}(2,24)=$ $3.97, \mathrm{p}<.05]$, and a nonsignificant Groups by Blocks interaction $(\mathrm{p}>.10)$.

Tukey (a) paired comparisons between group mean running speeds for Blocks 14, 15, and 20 showed that Group NC ran significantly faster than Groups C and NT for each block $(p<.05)$. However, Groups $C$ and NT did not exhibit significantly different speeds on Blocks 14,15 , and $20(\mathrm{p}>.10)$.

\section{DISCUSSION}

The findings supported the learned helplessness hypothesis that noncontrollability should produce more resistance to extinction than controllability or no treatment. In other words, the subjects (Group NC) who received noncontingent reward in the operant chamber (Stage 2) may have learned that their behavior had no control over its consequences or was ineffective in producing consistent rewards. If nonresponding during extinction is a voluntary (learned) response, then Group NC should have shown more resistance to extinction, since studies show that uncontrollability leads to deficits in instrumental learning in subsequent situations (e.g., Overmier \& Seligman, 1967; Rosellini \& Seligman, 1975; Seligman, 1975; Seligman \& Maier, 1967; Wheatley et al., 1977). The implications of the present results suggest that the learned helplessness model can be extended to predicting performance during extinction. The present results may also imply that the partial reinforcement effect in extinction (PREE) can, at least partly, be attributed to a learned helplessness phenomenon. In other words, subjects receiving partial reinforcement (PRF) may be methodologically similar to Group NC in the present study. Whether a PRF group receives reward or no reward is not contingent on "getting down the alley." Hence, the PRF animals may be acquiring learned helplessness, which may explain why they are more resistant to extinction than a CRF group.

It should be mentioned, however, that the present findings can be interpreted according to Amsel's (1958) conditioned frustration theory. Group NC may have learned to anticipate food in the goal cup. If an approach response was followed by no food, frustration may have occurred and become conditioned to the chamber cues. Conditioned frustration (rf-sf), elicited by the chamber cues may have occasionally been followed by reward in the goal cup. Hence, Group NC subjects may have learned to approach in the presence of frustration stimuli. This, of course, could explain why they showed more resistance to extinction than Groups $\mathrm{C}$ and NT. However, the experimenters noted the fact that Group NC was generally inactive and hovered around the goal cup during Stage 2 , which may preclude a frustration interpretation.

\section{REFERENCES}

Amsel, A. The role of frustration nonreward in noncontinuous reward. Psychological Bulletin, 1958, 95, 102-119.

Ludvigson, H. W., \& GAY, S. Differential reward conditioning: $\mathrm{S}-$ contrast as a function of the magnitude of $\mathrm{S}+$. Psychonomic Science, 1966, 5, 289-290.

Overmier, J. B., \& Seligman, M. E. P. Effects of inescapable shock upon subsequent escape and avoidance learning. Journal of Comparative and Physiological Psychology, 1967, 63, 23-33. 
Rosellini, R. A., \& Seligman, M. E. P. Frustration and learned helplessness. Journal of Experimental Psychology: Animal Behavior Processes, 1975, 104, 149-157.

Seligman, M. E. P. Helplessness: On depression, development, and death. San Francisco: Freeman, 1975.

Seligman, M. E. P., \& Maier, S. F. Failure to escape traumatic shock. Journal of Experimental Psychology, 1967, 74, 1-9.
Wheatley, K. L., Walker, R. L., \& Miles, R. C. Acquisition of barpressing in rats following experience with response independent food. Animal Learning \& Behavior, 1977, 5, 236-242.

(Received for publication April 20, 1981.) 